\title{
Indomethacin reproducibly induces metamorphosis in Cassiopea xamachana scyphistomae
}

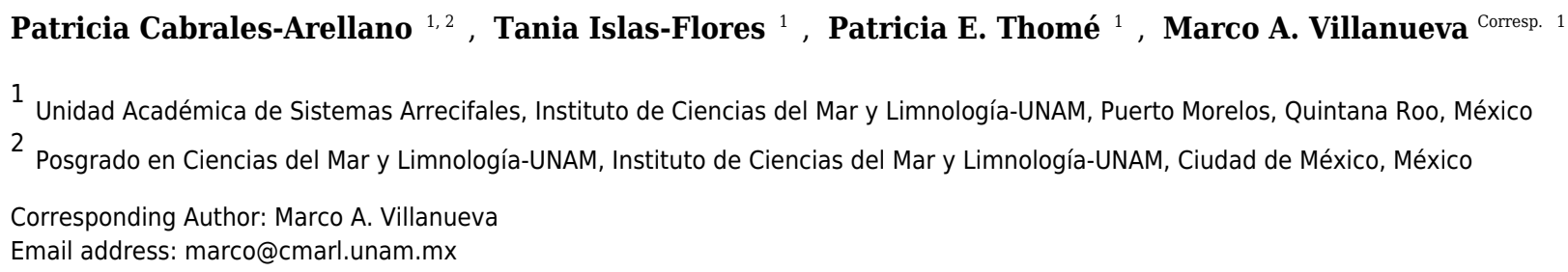

Cassiopea xamachana jellyfish are an attractive model system to study metamorphosis and/or cnidarian-dinoflagellate symbiosis due to the ease of cultivation of their planula larvae and scyphistomae through their asexual cycle, in which the latter can bud new larvae and continue the cycle without differentiation into ephyrae. Then, a subsequent induction of metamorphosis and full differentiation into ephyrae is believed to occur when the symbionts are acquired by the scyphistomae. Although strobilation induction and differentiation into ephyrae can be accomplished in various ways, a controlled, reproducible metamorphosis induction has not been reported. Such controlled metamorphosis induction is necessary for an ensured synchronicity and reproducibility of biological, biochemical and molecular analyses. For this purpose, we tested if differentiation could be pharmacologically stimulated as in Aurelia aurita, by the metamorphic inducers thyroxine, $\mathrm{KI}, \mathrm{Nal}$, lugol's iodine, $\mathrm{H}_{2} \mathrm{O}_{2}$, indomethacin, or retinol. We found reproducibly induced strobilation by $50 \mu \mathrm{M}$ indomethacin after 6 days of exposure, and $10-25 \mu \mathrm{M}$ after 7 days. Strobilation under optimal conditions reached $80-100 \%$ with subsequent ephyrae release after exposure. Thyroxine yielded inconsistent results as it caused strobilation occasionally, while all other chemicals had no effect. Thus, indomethacin can be used as a convenient tool for assessment of biological phenomena through a controlled metamorphic process in C. xamachana scyphistomae. 
1 Indomethacin reproducibly induces metamorphosis in Cassiopea xamachana scyphistomae

2

3 Patricia Cabrales-Arellano ${ }^{1,2}$, Tania Islas-Flores ${ }^{1}$, Patricia E. Thomé ${ }^{1}$ and Marco A. Villanueva ${ }^{1,}$ 43

5

$6 \quad{ }^{1}$ Instituto de Ciencias del Mar y Limnología

$7 \quad$ Unidad Académica de Sistemas Arrecifales

8 Universidad Nacional Autónoma de México-UNAM

9 Prol. Avenida Niños Héroes S/N

10 Puerto Morelos, Quintana Roo 77580, México

11

12 2Posgrado en Ciencias del Mar y Limnología

13 Instituto de Ciencias del Mar y Limnología

14 Universidad Nacional Autónoma de México

15 Circuito Exterior S/N

16 Ciudad Universitaria, Delegación Coyoacán

17 Ciudad de México, 04510, México

18

$19{ }^{3}$ Corresponding author

20 E-mail: marco@cmarl.unam.mx

21

22 


\section{Abstract}

25

Cassiopea xamachana jellyfish are an attractive model system to study metamorphosis and/or

27 cnidarian-dinoflagellate symbiosis due to the ease of cultivation of their planula larvae and

28 scyphistomae, in which the latter can bud new larvae and continue the cycle without

29 differentiation into ephyrae. Then, a subsequent induction of metamorphosis and full

30 differentiation into ephyrae is believed to occur when the symbionts are acquired by the

31 scyphistomae. Although strobilation induction and differentiation into ephyrae can be

32 accomplished in various ways, a controlled, reproducible metamorphosis induction has not been

33 reported. Such controlled metamorphosis induction is necessary for an ensured synchronicity and

34 reproducibility of biological, biochemical and molecular analyses. For this purpose, we tested if

35 differentiation could be pharmacologically stimulated as in Aurelia aurita, by the metamorphic

36 inducers thyroxine, KI, NaI, lugol's iodine, $\mathrm{H}_{2} \mathrm{O}_{2}$, indomethacin, retinol, and 9-cis-retinoic acid.

37 We found reproducibly induced strobilation by $50 \mu \mathrm{M}$ indomethacin after 6 days of exposure,

38 and $10-25 \mu \mathrm{M}$ after 7 days. Strobilation under optimal conditions reached $80-100 \%$ with

39 subsequent ephyrae release after exposure. Nine-cis- retinoic acid induced strobilation at longer

40 times but this was not synchronous. Thyroxine yielded inconsistent results as it caused

41 strobilation occasionally, while all other chemicals had no effect. Thus, indomethacin can be

42 used as a convenient tool for assessment of biological phenomena through a controlled

43 metamorphic process in C. xamachana scyphistomae.

Introduction

46 Cnidarian-dinoflagellate symbioses are fundamental components of coral reefs and other tropical 47 ecosystems. The biochemical and molecular mechanisms underlying such symbiotic 
48 relationships remain poorly understood, although important efforts have been carried out to

49 describe transcription profiles in several cnidarian-dinoflagellate systems (Weis \& Levine, 1996;

50 Richier et al., 2008; DeSalvo et al., 2010). Due to the difficulty of establishing appropriate

51 models for the study of coral-dinoflagellate symbiosis, new emerging models such as Aiptasia

52 pulchella, Anemonia viridis anemonae, and the jellyfish Cassiopea xamachana, have been used

53 for various biochemical, molecular and transcriptomics approaches (Kuo et al., 2004; Markell \&

54 Wood-Charlson, 2010; Moya et al., 2012). The jellyfish C. xamachana offers various advantages

55 for such studies since it can be propagated both sexually and asexually. The sexual cycle occurs

56 when the male and female gametes produce a planula larva, which can settle and metamorphose

57 to a polyp or scyphistoma (Colley \& Trench, 1983). This scyphistoma can then acquire

58 symbionts and differentiate to an ephyra, which will subsequently become an adult jellyfish (Fig.

59 1). If the scyphistomae do not acquire the symbiont, they can bud out new larvae, which can

60 settle again and form new scyphistomae to perpetuate the cycle (Fig. 1; Colley \& Trench, 1983).

61 This physiological process represents an advantage to study the metamorphosis of the jellyfish

62 under controlled laboratory conditions. However, in our hands, we have obtained inconsistent

63 results with the induction of metamorphosis in C. xamachana with the infecting symbiont.

64 Furthermore, we have consistently observed symbionts within our asexual scyphistomae

65 cultures, which stay perpetuating the cycle without strobilation or progression to the expected

66 metamorphosis. Since we are interested in studying signal-transduction processes that occur

67 during the metamorphic process, we required a reproducible and consistent procedure to induce

68 the metamorphosis in C. xamachana scyphistomae.

69 Several compounds have been reported for chemical induction of metamorphosis in 70 jellyfish, mostly Aurelia aurita, which does not undergo symbiosis with Symbiodinium. These 
71 include indomethacin (Kuniyoshi et al., 2012), $\mathrm{H}_{2} \mathrm{O}_{2}$ (Berking et al., 2005), thyroxine and iodine

72 (Spangenberg, 1967; 1974), retinol, 9-cis-retinoic acid and the indole compounds 5-methoxy-2-

73 methyl-3-indoleacetic acid, 5-methoxyindole-2-carboxylic acid, 2-methylindole, and 5-methoxy-

74 2-methylindole (Fuchs et al., 2014). One report documenting the use of the iodine-containing

75 compound lugol as inducer of metamorphosis in Cassiopea spp. jellyfish exists (Pierce, 2005). In

76 that study, $100 \%$ of strobilation was shown to occur after a week of exposure to $0.06 \mathrm{ppm}$.

77 However, the induction of strobilation in the scyphistomae of this jellyfish with a single defined

78 compound has not been documented.

In this work, we were able to consistently and reproducibly induce metamorphosis in $C$.

80 xamachana scyphistomae by applying a single dose within a range of $0.5-50 \mu \mathrm{M}$ indomethacin at

$8125 \pm 2{ }^{\circ} \mathrm{C}$ and $200 \mu$ mole quanta $\mathrm{m}^{-2} \mathrm{~s}^{-1}$ under $12 \mathrm{~h}$ light/dark photoperiod cycles. These results

82 place indomethacin as a tool for biochemical and/or molecular studies through a controlled

83 metamorphic process in C. xamachana scyphistomae.

84

85 Materials and Methods

86 Animal rearing

87 Cassiopea xamachana scyphistomae were a kind gift of the Xcaret Park aquarium in Quintana

88 Roo, México. The animals were reared in Petri plates containing filtered seawater and kept at 25

$89 \pm 2{ }^{\circ} \mathrm{C}$ under darkness and only exposed to artificial laboratory light when fed. They were fed a

90 diet of live Artemia salina nauplii every two days and cleaned from debris after feeding.

\section{Chemicals}


92 Thyroxine, KI, NaI, lugol's iodine (potassium tiiodide), indomethacin, retinol, 9-cis-retinoic acid

93 and dimethylsulfoxide (DMSO) were from Sigma. $\mathrm{H}_{2} \mathrm{O}_{2}$ was purchased from the local pharmacy.

\section{Experimental treatments}

95 The animals were stopped from feeding two days prior to exposure to the chemicals. Under

96 flourescence microscopic we observed that all the scyphistoma had a few symbionts (Fig. 2). The

97 treatments were applied under the laboratory artificial ambient light and when started, the

98 scyphistomae were placed under a $12 \mathrm{~h}$ light/dark cycle with fluorescent lamps at $70 \mu$ moles

99 quanta $\mathrm{m}^{-2} \mathrm{~s}^{-1}$. Five scyphistomae with an average head diameter of approximately $2.5 \mathrm{~mm}$ were

100 placed into individual wells of a 6-well microtiter plate with $5 \mathrm{ml}$ sterile artificial seawater

101 (Instant Ocean; Cincinnati, OH) and triplicate wells were used for each experimental treatment.

102 The treatments were as follows: thyroxine at $0.1,1,5,10,20,50$ and $100 \mu \mathrm{M}$; retinol at $0.5,1$

103 and $5 \mu \mathrm{M} ; 1,10$ and $100 \mathrm{nM} \mathrm{H}_{2} \mathrm{O}_{2} ; 100 \mu \mathrm{M}$ glucose; $100 \mu \mathrm{M}$ glycine; 50, 100 and $300 \mu \mathrm{M}$ L-

104 tyrosine; 50, 100 and $300 \mu \mathrm{M} \mathrm{NaI} ; 100 \mu \mathrm{M} \mathrm{KI} ; 0.01 \%$ (v/v) glycerol; and lugol at $263 \mu \mathrm{L} / \mathrm{L}$

105 (equivalent to $130 \mathrm{mg} / \mathrm{mL}$ of iodine), and 9-cis-retinoic acid at 1 and $25 \mu \mathrm{M}$ (Fuchs et al., 2014).

106 Indomethacin was tested at $0.5,1,5,10,25,50,100,200$ and $500 \mu \mathrm{M} .1 \mu \mathrm{M}$ of 9 -cis-retinoic

107 acid according with Fuchs et al., 2014 was tested. Controls consisting of filtered seawater with or

108 without DMSO (as indomethacin was dissolved in DMSO) were also used.

\section{Microscopy}

110 Induction of metamorphosis to strobilation was monitored visually under a Leica MZ125 (Leica

111 Microsystems) stereomicroscope. In order to monitor for the presence of symbionts inside the

112 various stages of the animals, observations were carried out under a Zeiss Axioskop

113 epifluorescence microscope with a rhodamine filter. Larvae, scyphistomae or strobilae were 
114 previously anesthetized by $10 \mathrm{~min}$ incubations with $10 \% \mathrm{MgCl}_{2}$ in filtered seawater at $25 \pm 2{ }^{\circ} \mathrm{C}$,

115 and then placed on the microscope slides for the observations.

\section{Statistical analysis}

117 Data were statistically analyzed using the R project software (www.r-project.org) with a Nested 118 ANOVA (days within different concentrations of indomethacin) and a Student-Newman-Kleus 119 post hoc analysis.

120

\section{Results}

\section{Symbionts are present at various stages of non-strobilating $C$. xamachana}

123 In our hands, asexually reared C. xamachana at different physiological stages (maintained in the

124 dark and placed at ambient light only for feeding), consistently showed the presence of

125 symbionts. Larvae were observed to contain endosymbionts detected as dark spots under light

126 microscopy (Fig. 2a, arrows). The same spots showed the characteristic chlorophyll

127 autofluorescence under fluorescence microscopy (Fig. 2d, arrows). Similarly, endosymbionts

128 were also consistently detected in tentacles at the scyphistoma stage under both light (Fig. 2b)

129 and fluorescence (Fig. 2e) microscopy. Even though endosymbionts had been clearly acquired in

130 these two physiological stages, infected scyphistomae did not strobilate and/or differentiate to

131 ephyrae. Comparatively, a strobilating scyphistoma also contained a significant load of

132 endosymbionts (Figs. 2c and f). Thus, in our hands, we obtained inconsistent results with the

133 induction of strobilation and metamorphosis in C. xamachana with the symbiont. Thornhill et al.

134 (2006), reported that when the densities of the Symbiodinium reached between 10,000 to 50,000 
135 per scyphistoma, these stimulated the induction of strobilation; but this process could take

136 around 3 to 5 months. Also, Rahat and Adar (1980), evidenced the importance of temperature in

137 the metamorphic process in both symbiotic and aposymbiotic Cassiopea scyphistomae; however

138 this induction was not simultaneous. Therefore, we sought alternative methods to induce a

139 reproducible and synchronous scyphistomae strobilation and subsequent metamorphosis.

\section{Indomethacin reproducibly induces strobilation}

141 After testing several chemicals in an attempt to induce strobilation in C. xamachana

142 scyphistomae (see below), we found a consistent induction with indomethacin whereas no

143 induction was observed when plain seawater or seawater with the vehicle DMSO were used as

144 negative controls (Fig. 3). We tested a range of 0.5 to $500 \mu \mathrm{M}$ indomethacin concentrations to

145 induce strobilation. A nested ANOVA analysis indicated significant differences between

146 concentrations $\left(\mathrm{DF}=6, \mathrm{~F}=73.022, \mathrm{p}=2.2 \mathrm{E}^{-16}\right)$ and days within each concentration $(\mathrm{DF}=21$,

$\left.147 \mathrm{~F}=12.889, \mathrm{p}=1.57 \mathrm{E}^{-14}\right)$. A Student-Newman-Kleus post hoc analysis grouped days within each

148 concentration $(p<0.01)$ (Fig. 4). Strobilation of some scyphistomae began on day 5, when the

149 indomethacin concentration was at least $5 \mu \mathrm{M}$ (Fig. 4, white bar), but it was not uniform and

150 only $50 \%$ strobilation was observed at $50 \mu \mathrm{M}$ concentration at this time (Fig. 4, white bar). After

151 day 6, all scyphistomae began to strobilate within $24 \mathrm{~h}$, and all the indomethacin concentration

152 treatments promoted strobilation (Fig. 4, light gray bar). The indomethacin concentrations of $0.5-$

$1535 \mu \mathrm{M}$ were directly proportional to the percentage strobilation up to the 6th day; however,

154 strobilation became uniform only after the 7 th day. Strobilation seemed to induce a spontaneous

155 synchrony of all the strobila since release of ephyrae occurred in all of them at $7 \mathrm{~d}$ independent

156 of their time of strobilation. Thus, the optimum indomethacin concentration for a maximum

157 strobilation induction in a shorter period of time (6 d) was $50 \mu \mathrm{M}$. Indomethacin at $50 \mu \mathrm{M}$ also 
158 induced strobilation in the dark but the maximum was achieved at $10 \mathrm{~d}$ (results exactly the same

159 as $0.5 \mu \mathrm{M}$ indomethacin in Supplementary Table 1), indicating that the lack of photoperiod

160 affects the process negatively. In addition, a lower temperature of $22{ }^{\circ} \mathrm{C}$ also delayed the

161 strobilation process to $10 \mathrm{~d}$ (results exactly the same as $0.5 \mu \mathrm{M}$ indomethacin in Supplementary

162 Table 1). These data suggest that this process could be further manipulated by temperature and

163 illumination conditions to accelerate or delay metamorphosis. When indomethacin

164 concentrations higher than $100 \mu \mathrm{M}$ were tested, they were lethal to the scyphistomae $(*$ in

165 Supplementary Table 1). It is important to mention that after indomethacin-induced strobilation,

166 the scyphistomae could not be recovered for further asexual propagation.

\section{Only indomethacin yielded reproducible and consistent results}

168 In addition to indomethacin, we tested glucose, glycine, glycerol, thyroxine, L-tyrosine, KI, NaI,

169 potassium triiodide (lugol's iodine), $\mathrm{H}_{2} \mathrm{O}_{2}$, and retinol, and 9-cis-retinoic acid as inducers of

170 metamorphosis in C.xamachana scyphistomae under the same temperature and light conditions

171 as indomethacin. We used thyroxine and some iodine chemicals because previous reports

172 documented the use of this hormone and the iodine-based compound lugol to induce strobilation

173 in jellyfish scyphistomae (Spangenberg, 1974; Pierce, 2005). Thyroxine yielded inconsistent

174 results. In all cases, the concentrations were non-lethal but strobilation signs appeared only with

$175100 \mu \mathrm{M}$ thyroxine (supplemenary Table 1) and subsequent ephyrae release occurred only once.

176 On the other hand, $0.5,1$ and $5 \mu \mathrm{M}$ retinol did not have any effect on the C. xamachana

177 scyphistomae and the result was identical as the untreated or mock controls (Fig. 2 and

178 supplementary Table 1). Conversely, 9-cis-retinoic acid was able to induce the strobilation

179 process, but it was slower and not synchronized compared with the indomethacin treatments

180 (Fig. 5). We used two concentrations (1 and $25 \mu \mathrm{M})$ for 9-cis-retinoic acid, but the highest was 
181 lethal (all scyphistomae died). Similarly, glucose, glycine, glycerol, L-tyrosine, KI, NaI, lugol

182 and $\mathrm{H}_{2} \mathrm{O}_{2}$ were used at a wide range of concentrations but yielded inconsistent or no induction as 183 well (Supplementary Table 1).

184

\section{Discussion}

186 Indomethacin induction of metamorphosis occurred consistently and in a reproducible manner in

187 C. xamachana scyphistomae. The induction was effective at a range of concentrations of 5 to 50

$188 \mu \mathrm{M}$ which was within the concentration range observed by Kuniyoshi et al. (2012) for $A$. aurita

189 (2.5 to $20 \mu \mathrm{M})$. They reported that, in the case of $A$. aurita induction, the strobilation was dose-

190 dependent, where metamorphosis was induced with the highest doses at $9 \mathrm{~d}$ and with the lowest

191 ones at $14 \mathrm{~d}$ of treatment (Kuniyoshi et al., 2012). We obtained similar results in the sense that at

$1920.5-1 \mu \mathrm{M}$ strobilation did not occur at $5 \mathrm{~d}$, whereas it did happen at 5-50 $\mu \mathrm{M}$. In addition,

193 maximum percent strobilation was achieved at $8 \mathrm{~d}$ with 10-50 $\mu \mathrm{M}$, whereas a statistically

194 significant lower percent strobilation occurred with $1 \mu \mathrm{M}$ indomethacin tratment (Fig. 4).

195 Furthermore, strobilation was uniform after the 7 th day in the 5-50 $\mu \mathrm{M}$ range. Conversely,

196 thyroxine, which is the protocol inducer for $A$. aurita, yielded inconsistent results as it only

197 caused strobilation occasionally, while all other chemicals had no effect (Supplementary Table

198 1). Only 9-cis-retinoic acid was also effective at inducing metamorphosis, but at slower times

199 and with an apparent lack of synchronicity. Thus, this compound does not represent a good

200 choice as strobilation inducer for C. xamachana.

201 We do not know through which biochemical mechanism is indomethacin capable of

202 inducing strobilation in C. xamachana scyphistomae. Indomethacin is an inhibitor of the 
203 cyclooxygenase (COX) enzyme, and therefore of the prostaglandin (PG) biosynthesis; however,

204 when other COX inhibitors (such as aspirin, ibuprofen, etc.) were used, they did not stimulate

205 strobilation in A. aurita. Similarly, when the synthesis of arachidonic acid (which is the COX

206 substrate in the prostaglandin biosynthesis pathway) was inhibited, strobilation did not occur

207 (Kuniyoshi et al., 2012). Thus, the COX pathway of prostaglandin biosynthesis does not seem to

208 be the mechanism by which indomethacin induces metamorphosis in these cnidarians. This is

209 also consistent with conflicting results on indomethacin action in mammalian models, where it

210 appears to be involved in multiple pathways. For example, indomethacin can inhibit the

211 cyclooxygenase $(\mathrm{COX})$ pathway for prostaglandin $(\mathrm{PG})$ biosynthesis, which is, in turn,

212 synthesized from arachidonic acid (Smith et al., 2011). However, in some cases, indomethacin

213 did not inhibit COX expression, suggesting that there is an alternative COX-independent

214 indomethacin pathway (Tegeder et al., 2001). Recently, evidence at the proteomic level has

215 suggested the involvement of the Wnt1 signaling pathway without COX activation upon

216 indomethacin treatment in colon cancer cells (Cheng et al., 2013). This is consistent with the

217 proposed role of the Wnt1 pathway in cnidarian developmental processes (Holstein, 2008).

218 Recently, a peptide hormone with structural similarity to indole strobilation inducer chemicals

219 such as indomethacin has been described as the active molecule to induce strobilation in $A$.

220 aurita (Fuchs et al., 2014). Thus, it is likely that indomethacin acts mimicking such peptide

221 hormone action.

\section{Conclusions}


224 This work demonstrates that indomethacin can be used as a reliable chemical inducer of

225 metamorphosis in C. xamachana scyphistomae in a consistent and reproducible manner and that

226 this induction may be further manipulated with light and temperature. After the strobilation onset

227 in all scyphistomae, they seem to spontaneously synchronize to produce ephyrae release on the

228 same day. This reproducible chemical induction of strobilation provides a powerful tool for

229 biological, biochemical and molecular analyses of the metamorphic process under controlled

230 conditions.

231

\section{Acknowledgements}

233 We thank Claudia Morera, Anthony Rashuam-Cerdán and Adriana Córdoba-Isunza for technical

234 help. We also thank Luis P. Suescún-Bolívar for help with the statistical analysis and Ana Cerón 235 of Xcaret Park for the scyphistoma donation.

236

237

References

Berking, S., N. Czech, M. Gerharz, K. Herrmann, U. Hoffmann, H. Raifer, G. Sekul, B. Siefker, A. Sommerei, and F. Vedder. 2005. A newly discovered oxidant defence system and its involvement in the development of Aurelia aurita (Scyphozoa, Cnidaria): reactive oxygen species and elemental iodine control medusa formation. Int. J. Dev. Biol. 49: 969976. doi: $10.1387 / \mathrm{ijdb} .052024 \mathrm{sb}$ 
243 Cheng, Y. L., G. Y. Zhang, C. Li, and J. Lin. 2013. Screening for novel protein targets of 244 indomethacin in HCT116 human colon cancer cells using proteomics. Oncol. Lett. 6: 1222-1228. doi: 10.3892/ol.2013.1560

246

247

248

249

250

251

252

253

254

255

256

257

258

259

260

261

Colley, N. J. and R. K. Trench. 1983. Selectivity in phagocytosis and persistence of symbiotic algae by the scyphistoma stage of the jellyfish Cassiopeia xamachana. Proc. R. Soc. Lond. 219: 61-82. doi: 10.1098/rspb.1983.0059

DeSalvo, M. K., S. Sunagawa, C. R. Voolstra, and M. Medina. 2010. Transcriptomic response to heat stress and bleaching in the elkhorn coral Acropora palmata. Mar. Ecol. Prog. Ser. 402: $97-113$. doi: $10.3354 / \operatorname{meps} 08372$

Fuchs, B., W. Wang, S. Graspeuntner, Y. Li, E. M. Herbst, P. Dirksen, A. M. Bohm, G. Hemmrich, F. Sommer, T. Domazet-Loso, U. C. Klostermeier, F. Anton-Erxleben, P. Rosenstiel, T. C. G. Bosch, and K. Khalturin. 2014. Regulation of polyp to jellyfish transition in Aurelia aurita. Curr. Biol. 24: 263-273. doi: 10.1016/j.cub.2013.12.003

Holstein, T. W. 2008. Wnt signaling in Cnidarians, p. 47-54. In E. Vincan [ed], Methods in Molecular Biology. Humana Press, New York. doi: 10.1007/978-1-60327-469-5

Kuniyoshi, H., I. Okumura, I. Kuroda, N. Tsujita, K. Arakawa, J. Shoji, T. Saito, and H. Osada. 2012. Indomethacin induction of metamorphosis from the asexual stage to sexual stage in the moon jellyfish, Aurelia aurita. Biosci. Biotechnol. Biochem. 76: 1397-1400. doi: 10.1271/bbb.120076 
262 Kuo, J., M. C. Chen, C. H. Lin, and L. S. Fang. 2004. Comparative gene expression in the

263

264

265

266

267

268

269

270

271

272

273

274

275

276

277

278

279

280

281 symbiotic and aposymbiotic Aiptasia pulchella by expressed sequence tag analysis. Biochem. Biophys. Res. Comm. 318: 176-186. doi: 10.1016/j.bbrc.2004.03.191

Markell, D. A., and E. M. Wood-Charlson. 2010. Immunocytochemical evidence that symbiotic algae secrete potential recognition signal molecules in hospite. Mar. Biol. 157: 1105111. doi: 10.1007/s00227-010-1392-x

Moya, A., P. Ganot, P. Furla, and C. Sabourault. 2012. The transcriptomic response to thermal stress is immediate, transient and potentiated by ultraviolet radiation in the sea anemone Anemonia viridis. Mol. Ecol. 21: 1158-1174. doi: 10.1111/j.1365-294X.2012.05458.x

Pierce, J. 2005. A system for mass culture of upside-down jellyfish Cassiopea spp as a potential food item for medusivores in captivity. Int. Zoo Yb. 39: 62-69.

Rahat, M., O. Adar. 1980. Effect of symbiotic zooxanthellae and temperature on budding and strobilation in Cassiopeia andromeda (Eschscholz). Biol. Bull. 159: 394-401.

Richier, S., M. Rodriguez-Lanetty, C. E. Schnitzler, and V. M. Weis. 2008. Response of the symbiotic cnidarian Anthopleura elegantissima transcriptome to temperature and UV increase. Comp. Biochem. Physiol. 3: 283-289. doi: 10.1016/j.cbd.2008.08.001

Smith, W. L., Y. Urade, and P. J. Jakobsson. 2011. Enzymes of the cyclooxygenase pathways of prostanoid biosynthesis. Chem. Rev. 111: 5821-5865. doi: 10.1021/cr2002992

Spangenberg, D. B. 1967. Iodine induction of metamorphosis in Aurelia. J. Exp. Zool. 165: 441449. doi: 10.1002/jez.1401650312 
282 Spangenberg, D. B. 1974. Thyroxine in early strobilation in Aurelia aurita. J. Am. Zool. 14: 825-

283 831. doi: $10.1093 /$ icb/14.2.825

284 Tegeder, I., J. Pfeilschifter, and G. Geisslinger. 2001. Cyclooxygenase-independent actions of 285 cyclooxygenase inhibitors. FASEB J. 15: 2057-2072. doi: 10.1096/fj.01-0390rev

286

287

288

289

290

291

292

293

294 295 296 297 298 299 300 301

Thornhill, D. J., M. W. Daniel, T. D. LaJeunesse, G. W. Schmidt and W.K. Fitt. 2006. Natural infections of aposymbiotic scyphistomae from environmental pools of Symbiodinium. J. Exp. Mar. Biol. Ecol. 338: 50-56. doi.org/10.1016/j.jembe.2006.06.032.

Weis, V. M., and R. P. Levine. 1996. Differential protein profiles reflect the different lifestyles of symbiotic and aposymbiotic Anthopleura elegantissima, a sea anemone from temperate waters. J. Exp. Biol. 199: 883-892.

\section{Figure Legends}

Figure 1. Life cycle of Cassiopea xamachana. The cycle starts with sexual reproduction (1, solid lines), when adult jellyfish release their gametes into the water column. There, sperm-fertilized eggs become free-living larval ciliates. Once the swimming larvae identifies a suitable substrate, it settles and develops into a scyphistomae. The final stage is thought to ensue once Symbiodinium has been acquired by the scyphistomae, triggering metamorphosis, strobilation and ephyrae formation. The ephyrae are released into the water column creating a free-living jellyfish. In the asexual component (2, dashed lines), the scyphistoma develops a bud that is released into the enviroment as larva. It settles and metamorphoses to scyphistomae and the 
302 cycle perpetuates. In parallel, as the ephyra is released (3), it can regenerate into a newly formed

303 scyphistoma (dotted lines) and enter the asexual part of the cycle.

304

305 Figure 2. Microscopic analysis of Symbiodinium presence on three physiological stages of 306 Cassiopea xamachana. Endosymbiotic Symbiodinium cells were observed by their contrast 307 against the tissues by light microscopy (a-c), or by their chlorophyll autofluorescence (d-f). 308 Symbionts can be observed as dark or as fluorescent red dots, respectively, in a larval bud (a, d), 309 scyphistoma tentacles (b, e) and strobila (c, f). The arrows clearly show the symbionts as some 310 dark dots (a) corresponding to the same fluorescent ones (d) in a larval bud. Bars show the 311 corresponding dimension references in $\mu \mathrm{m}$.

Figure 3. Induction of strobilation with indomethacin. Indomethacin $(50 \mu \mathrm{M})$ was used to induce 314 strobilation on C. xamachana scyphistomae. All samples used for the strobilation induction 315 contained symbionts, but only those treated with indomethacin (c) strobilated. Changes can be 316 observed in the calyx of the scyphistomae at day 3, where they begin to show elongation. At day 3174 the tentacles start to retract and at day 5 all the tentacles are absent and the strobila begins 318 pulsating. On day 6 and 7, the ephyra matures and on day 8 it is released into the environment. 319 In contrast to the indomethacin treatment, the seawater (a) or DMSO (b) vehicle controls did not 320 result in strobilation. The experiment was repeated over three times independently with the same 321 results. 
323 Figure 4. Induction of strobilation under increasing indomethacin concentrations. Indomethacin

$324(0.5-50 \mu \mathrm{M})$ was used to induce strobilation in C. xamachana scyphistomae and percent

325 strobilation recorded after 5 (white bars), 6 (light gray bars), 7 (dark gray bars), and 8 (black

326 bars) d. Triplicate samples each containing five scyphistomae were used for each concentration

327 (see Materials and methods). Experiments were reproducibly performed at least five times.

328 Maximum strobilation within a shortest period of treatment was achieved with $50 \mu \mathrm{M}$

329 indomethacin at $6 \mathrm{~d}$. The bars show the average \pm the standard deviation. Post hoc analysis is 330 denoted by small letters at $p<0.01$.

332 Figure 5. Comparison of indomethacin and 9-cis-retinoic acid effects on strobilation.

333 Indomethacin at $50 \mu \mathrm{M}$ and 9-cis-retinoic acid at $1 \mu \mathrm{M}$ were used as inducers for the strobilation 334 of C. xamachana scyhpistomae, recorded from day 4 to day 10 after each treatment. Triplicate 335 samples containing 5 schyphistomae each, were followed. Indomethacin consistently induced 336 strobilation from day 5 on (black bars), whereas 9-cis-retinoic acid lagged behind even at day 10 337 (light gray bars). Error bars show the mean average \pm standard deviation.

339 Supplementary Table 1. Strobilation induction tests on Cassiopea xamachana scyphistomae with 340 all the chemicals used for the treatments and under various conditions. Strobilation was 341 monitored throughout $10 \mathrm{~d}$ of treatment at $25^{\circ} \mathrm{C}$ under photoperiod ( $12 \mathrm{~h} \mathrm{light} / 12 \mathrm{~h}$ dark). 342 Scyphistomae were mantained at $25^{\circ} \mathrm{C}$ for several months before the treatment. For each 343 replicate 3-5 scyphistomae were used; 3 replicates per treatment. ( - ) Indicates no changes were 344 detected. $(\sim)$ Indicates that signs of strobilation were detected. $(+)$ Indicates strobilation 
345 ocurred. ( *) Indicates inducer concentrations at which adverse effects on the polyps were 346 observed. FSW, Filtered Sea Water; ASW, Artificial Sea Water. 


\section{Figure 1}

Life cycle of Cassiopea xamachana.

The cycle starts with sexual reproduction (1, solid lines), when adult jellyfish release their gametes into the water column. There, sperm-fertilized eggs become free-living larval ciliates. Once the swimming larvae identifies a suitable substrate, it settles and develops into a scyphistomae. The final stage is thought to ensue once Symbiodinium has been acquired by the scyphistomae, triggering metamorphosis, strobilation and ephyrae formation. The ephyrae are released into the water column creating a free-living jellyfish. In the asexual component (2, dashed lines), the scyphistoma develops a bud that is released into the enviroment as larva. It settles and metamorphoses to scyphistomae and the cycle perpetuates. In parallel, as the ephyra is released (3), it can regenerate into a newly formed scyphistoma (dotted lines) and enter the asexual part of the cycle.

*Note: Auto Gamma Correction was used for the image. This only affects the reviewing manuscript. See original source image if needed for review. 


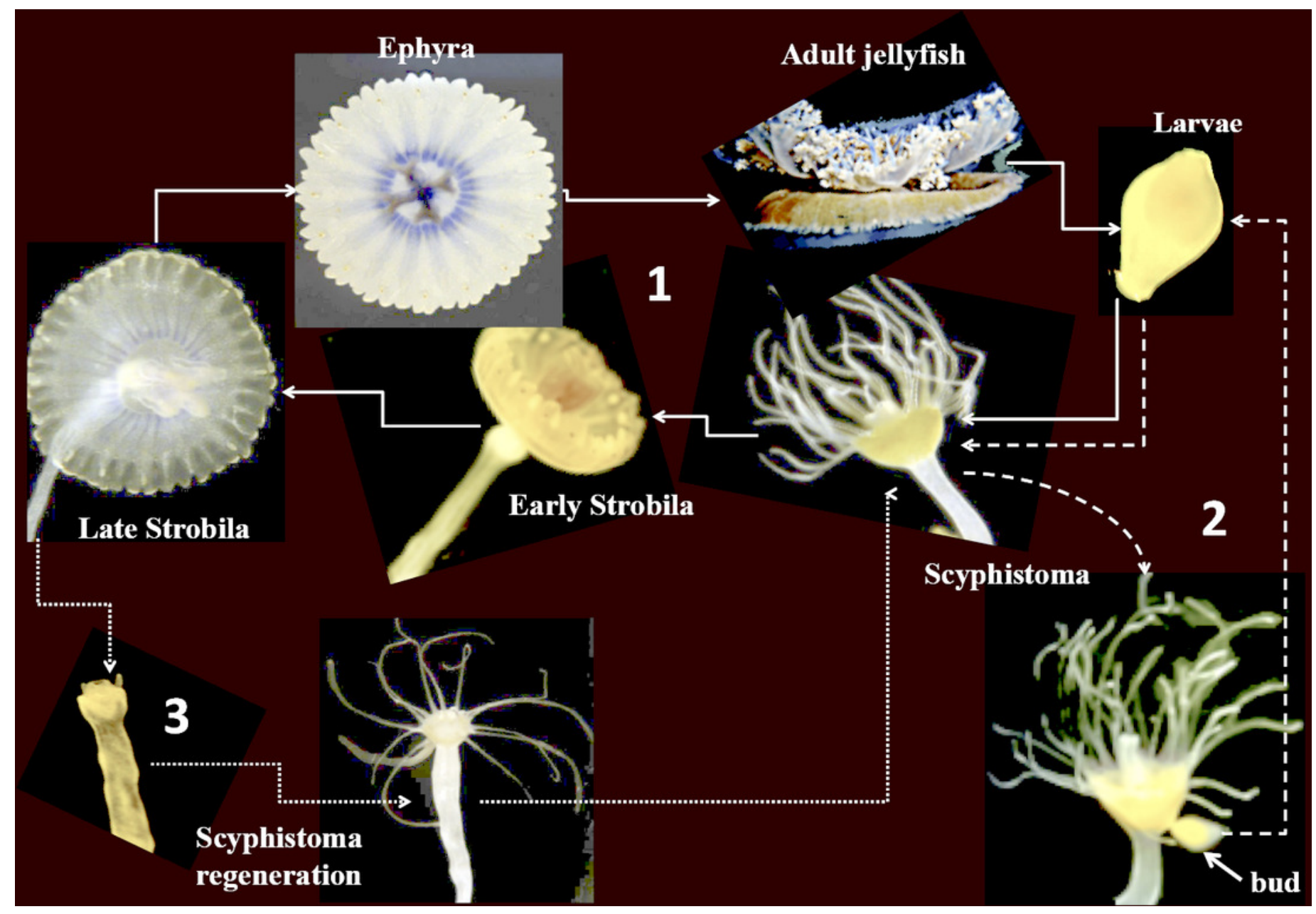




\section{Figure 2}

Microscopic analysis of Symbiodinium presence on three physiological stages of Cassiopea xamachana.

Endosymbiotic Symbiodinium cells were observed by their contrast against the tissues by light microscopy (a-c), or by their chlorophyll autofluorescence (d-f). Symbionts can be observed as dark or as fluorescent red dots, respectively, in a larval bud (a, d), scyphistoma tentacles (b, e) and strobila (c, f). The arrows clearly show the symbionts as some dark dots (a) corresponding to the same fluorescent ones (d) in a larval bud. Bars show the corresponding dimension references in $\mu \mathrm{m}$.

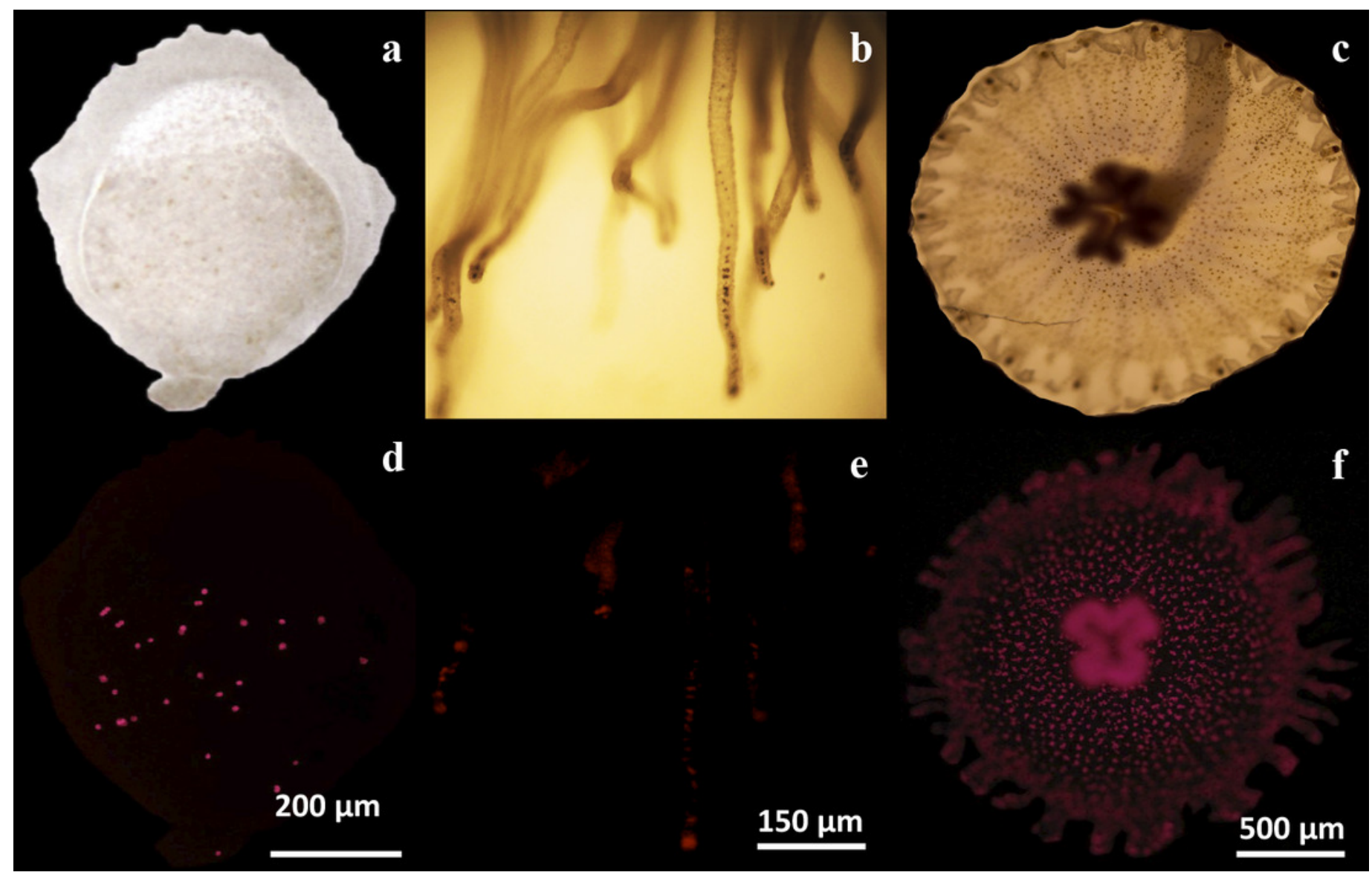




\section{Figure 3}

Induction of strobilation with indomethacin. Indomethacin (50 $\mu \mathrm{M})$ was used to induce strobilation on C. xamachana scyphistomae.

All samples used for the strobilation induction contained symbionts, but only those treated with indomethacin (c) strobilated. Changes can be observed in the calyx of the scyphistomae at day 3 , where they begin to show elongation. At day 4 the tentacles start to retract and at day 5 all the tentacles are absent and the strobila begins pulsating. On day 6 and 7, the ephyra matures and on day 8 it is released into the environment. In contrast to the indomethacin treatment, the seawater (a) or DMSO (b) vehicle controls did not result in strobilation. The experiment was repeated over three times independently with the same results.

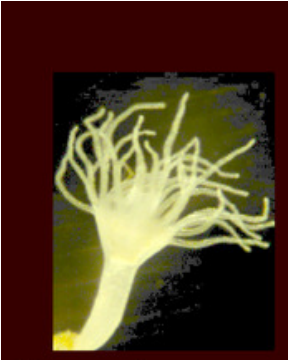

Days 1

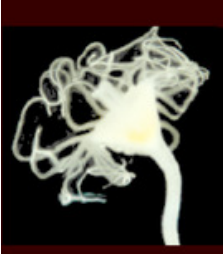

Days 1

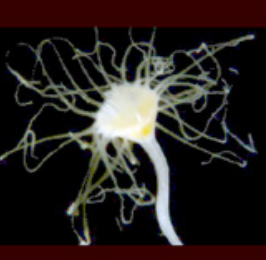

2

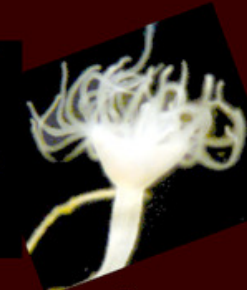

3

\section{a) Sea water}

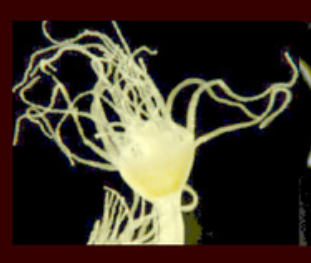

2

3

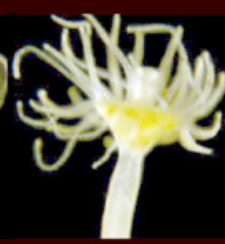

4

b) DMSO

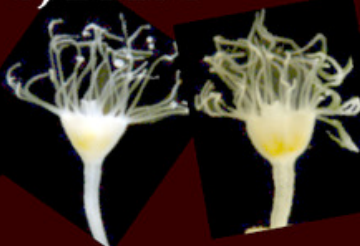

4

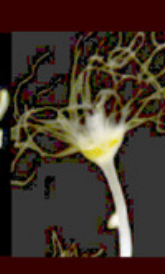

5

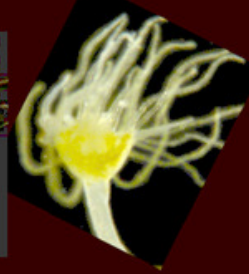

6

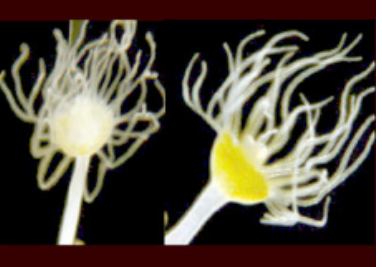

7

c) Indomethacin

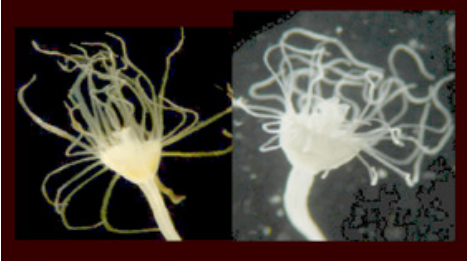

Days

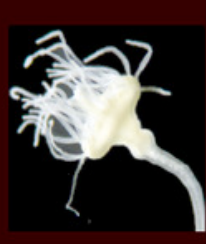

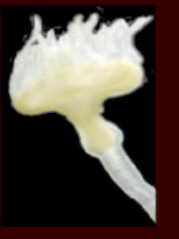

4

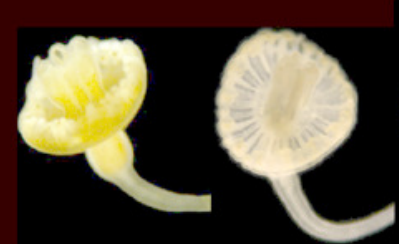

5

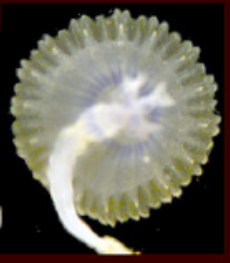

7

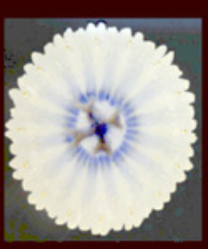

8 


\section{Figure 4}

Induction of strobilation under increasing indomethacin concentrations.

Indomethacin (0.5-50 $\mu \mathrm{M})$ was used to induce strobilation in C. xamachana scyphistomae and percent strobilation recorded after 5 (white bars), 6 (light gray bars), 7 (dark gray bars), and 8 (black bars) d. Triplicate samples each containing five scyphistomae were used for each concentration (see Materials and methods). Experiments were reproducibly performed at least five times. Maximum strobilation within a shortest period of treatment was achieved with $50 \mu \mathrm{M}$ indomethacin at $6 \mathrm{~d}$. The bars show the average \pm the standard deviation. Post hoc analysis is denoted by small letters at $p<0.01$.

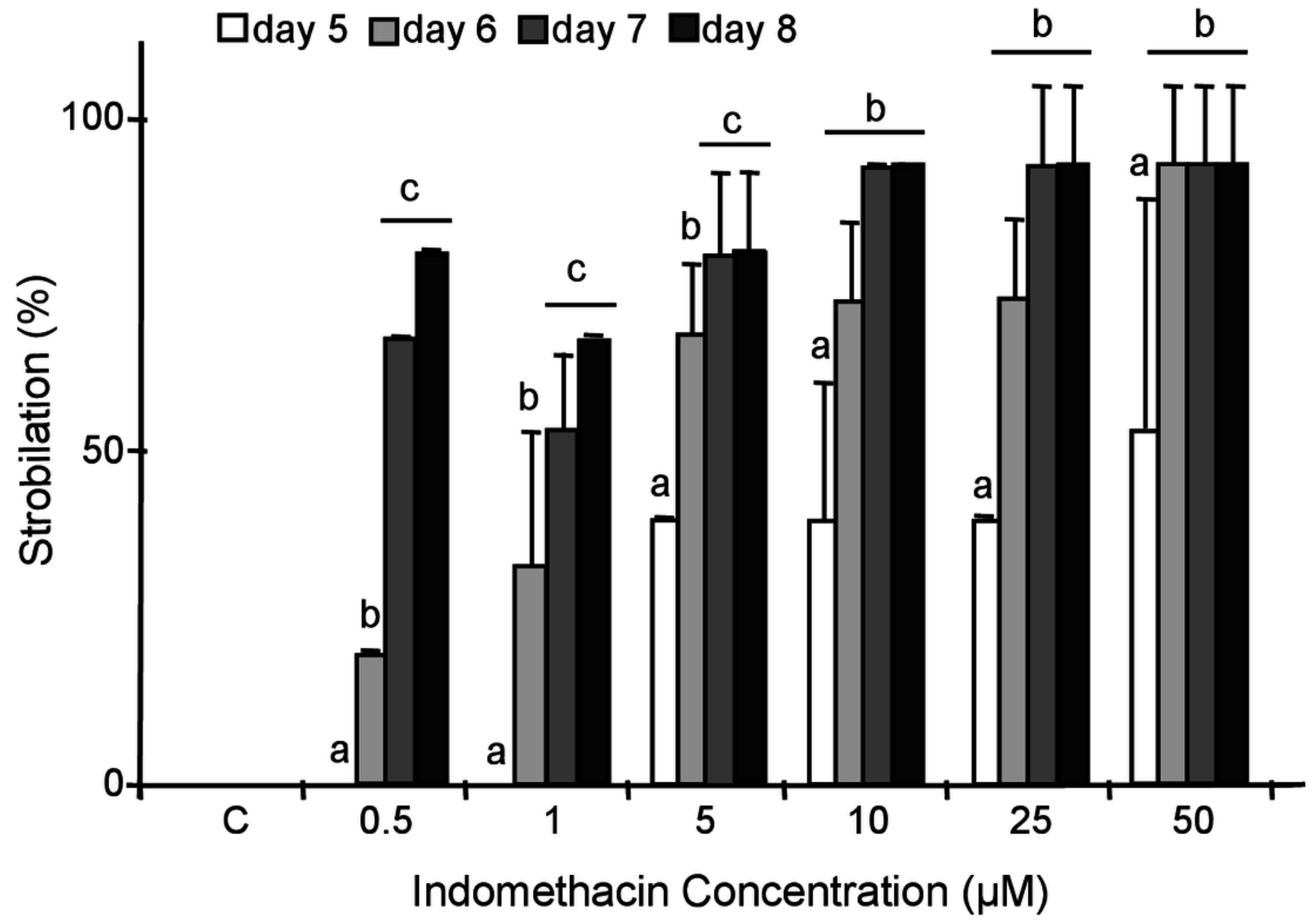




\section{Figure 5}

Comparison of indomethacin and 9-cis-retinoic acid effects on strobilation.

Indomethacin at $50 \mu \mathrm{M}$ and 9-cis-retinoic acid at $1 \mu \mathrm{M}$ were used as inducers for the strobilation of C. xamachana scyhpistomae, recorded from day 4 to day 10 after each treatment. Triplicate samples containing 5 schyphistomae each, were followed. Indomethacin consistently induced strobilation from day 5 on (black bars), whereas 9-cis-retinoic acid lagged behind even at day 10 (light gray bars). Error bars show the mean average \pm standard deviation.

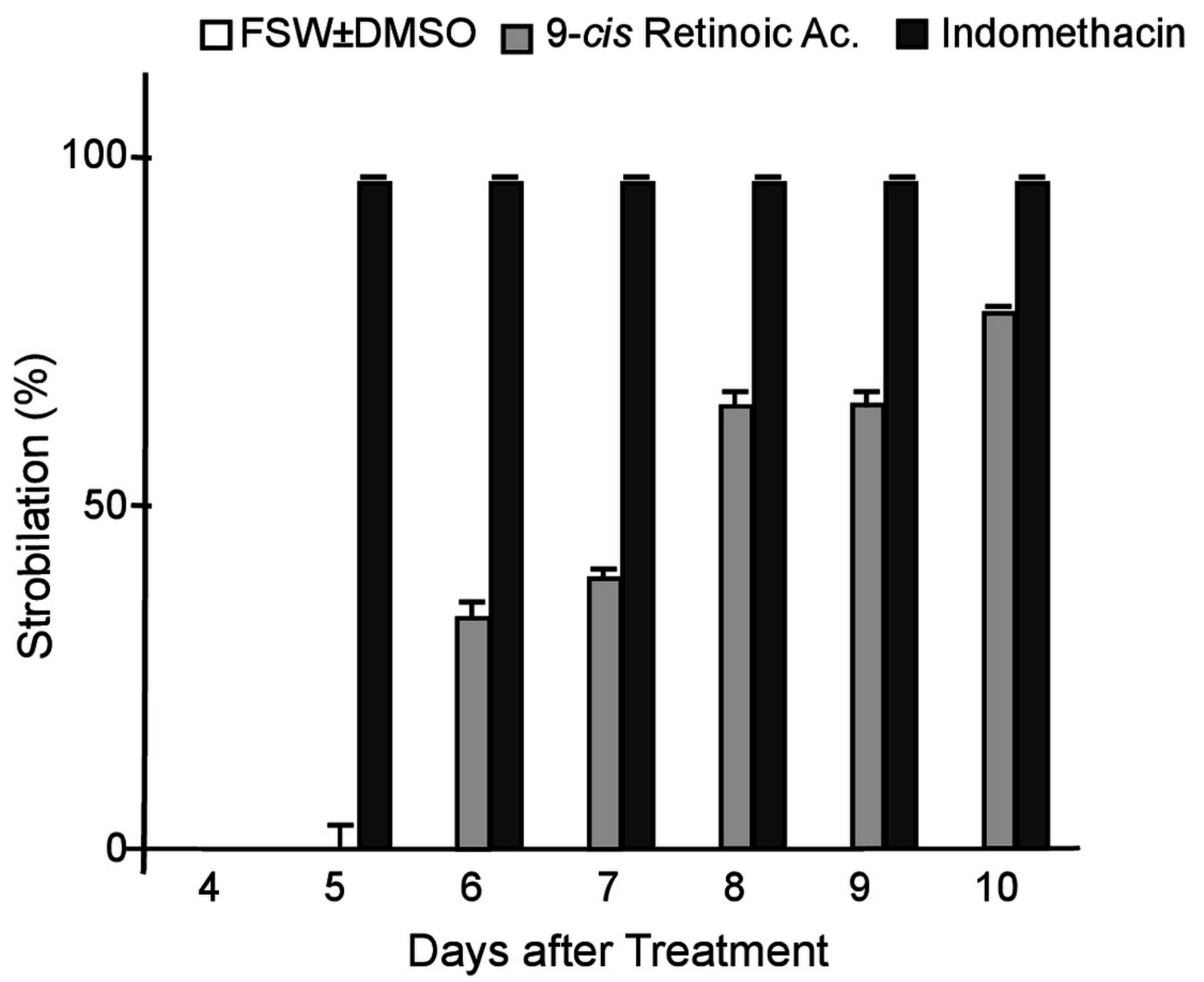

